weik; hiocup came on the next morning early; and the patient died about noon. On port mortem examination, alight peritonitis was found, and an adhesion of the omentum (not the strangulated portion) to the intestine, dragging it down, but without producing complete strangulation. (218.)

Out of the whole number of 64 cases (24 in the former report, and 40 in this) in which the operation was performed, 51 of the patients were men and 13 women; of this number 30 died, 25 men and 5 women. Among the patients who recorered are the youngest and oldest in the list, a girl sixten years old, and two men of seventy-seven.

The number of cases in the different months were, in January, 6 ; February, 1; March, 9 ; April, 2; May, 12; June, 2; July, 2; August, 9 ; September, 5 ; October, 3; November, 5 ; and December, 8.

Oxford, February 1535.

\section{SCIRRHOUS TUMOUR OF THE LOWER JAW.}

By ROBERT ELLIOTT, Esq., Senior Surgeon to the Chichester Infirmary.

George Bonny, a pale scrofulous-looking child, aged 21 years, was brought to the infirmary on the 18th of April, 1854. About a year previously, the mother discorered a small hard swelling inmediately under the lower jaw on the left side, which was treated as a symptom of common cold; but, as the tumour rapidly increased, he was taken to a medical man, who treated him. The tumour, however, made its progress without much pain, but with great rapidity, and it was determined by his friends and medical adviser to send him to the infirmary, where he arrived on the above date.

The disease consisted of a firm, hard tumour, developed from the lower border of the inferior maxilla of the left side, about the insertion of the canine tooth. It extended downwards into the carotid triangle of the neck, immediately under the platysma, and was there about the size of a cricket-ball. It ascended into the mouth on the inner side of the jaw, completely filling up the floor of the mouth, pushing the tongue upwards and outwards, and from its pressure behind, causing great difficulty of breathing, approaching suffocation. Very slight pain existed, and but fittle derangement of general health. On consultation with my colleagues, we determined that removal by operation was the only available chance of success; and on the 28th I proceeded to perform it in the following manner.
The patient being tharoughly under the influence of chloroform, the canine tooth of the left side was extracted; a semicircular incision was then made, which extended from nearly the articular process (see plate) across the tumour to the symphysis of the jaw; the facial artery was divided in this incision, but the blecding was arrested by pressure. The skin was then dissected upwards, so as to expose the jaw, which I then divided above the angle, and at the insertion of the canine tooth, by the means of bone forceps. The detached portion of the jaw was then turned outwands, and the tumour with little difficulty was dissected out. But little hæmorrhage resulted, although the carotid artery was seen beating at the bottom of the wound.

The edges of the incision were brought together with various ligatures and plasters; a compress of lint was then applied, and the child was placed in bed. Not a bad symptom occurred; there was rery slight reaction, and the whole wound nearly healed by the first intention.

May 30th. He was discharged this day, with little or no deformity. There was a slight discharge from a small superficial though healthy sinus. He could masticate freely.

Remarks. There can be no doubt that the disease was scirrhous, originating from the cancelli of the lower jaw, which, being hypertrophied, formed part and parcel of the tumour.

It is singular that this disease should exist in so young a child, particularly as neither scrofula nor cancer are known in his family; nor could he be ascertained to have suffered any injury. The immediate reparation of the mischief after the operation for the remoral of disease is not surprising. I have generally observed in scrofulous systems, that nature's whole efforts are thrown in to repair the breach when the enemy has retired; yet I have too frequently seen that the vis vitoe is incapable of repelling a second attack, as the anguis in herb $\hat{A}$ is invariably resident in the vital recesses of such subjects, defying the most strenuous efforts of remedial opposition. A return of disease may therefore, I fcar, be expected. There are also some points worthy of notice, viz., the ease with which mastication is performed after the loss of one-half of the jaw at so early a period; also the very slight, if any, deformity which remained. The latter circumstance has induced me to introduce a faithfully delineated accompanying sketch, for which I am indebted to $m y$ friend Mr. W.H. Brook, F.S.A. The Arawing was made on wood by Mr. Brewer of Red Lion Court.

I cannot close this history without acknowledging my obligations to my friend Mr. Newham, our house-surgeon, for his great attention to this case.

Chichester, February 1855.

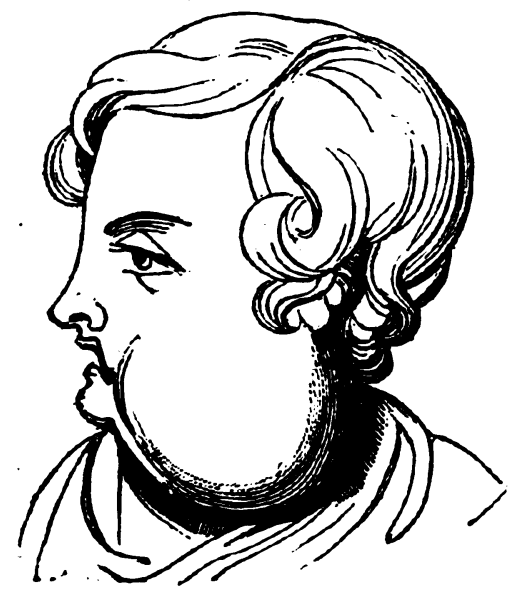

Side view.

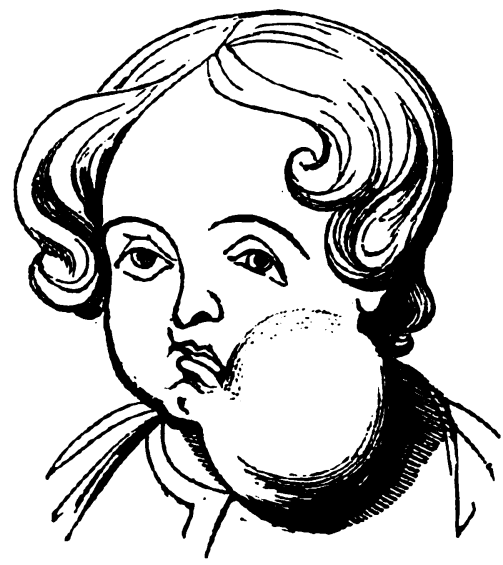

Front riow.

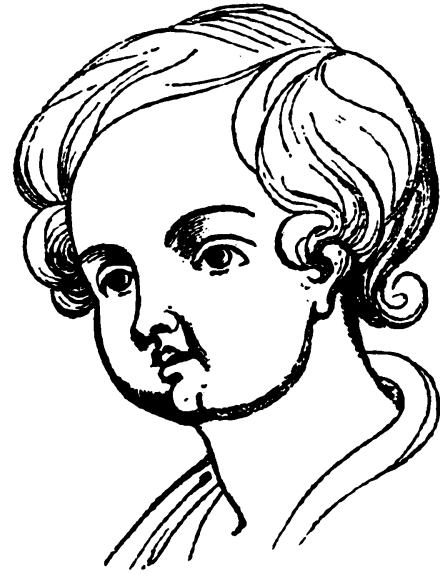

Ater operation. 